\title{
Are attempts to have impaired children justifiable?
}

K W Anstey

Couples should not be allowed to select either for or against deafness

$\mathrm{R}$ ecently, a US couple deliberately attempted to ensure the birth of a deaf child via artificial insemination. ${ }^{1}$ In opposing this action, I wish to focus on one argument they employ to support it, namely that in trying to have a deaf child, the women see themselves as no different from parents trying to have a girl. Girls can be discriminated against the same as deaf people and "black people have harder lives", one of them argues. They compare themselves to a minority group. ${ }^{2}$

In using this argument to justify their attempt to secure the birth of a deaf child, they make four claims:

1. It is not wrong to deliberately try to have a child who is expected to experience harm when the harms the child will experience are socially imposed.

2. As a group experiencing socially imposed harms, the deaf are to be understood as a minority group.

3. Women and people of colour also experience social harms, and are to be understood as minority groups.

4. Because the deaf, women, and people of colour are all groups experiencing socially imposed harms, distinctions should not be made between attempts to have a child who will be a member of one of these groups.

In reply, I will advance two arguments. First, I will argue that this couple's decision is inherently just. Here I will acknowledge that this couple's position draws a great deal of strength from its appeal to the experiences of women. My second argument will contend, however, that despite the reasonableness of this choice, the intentional selection of deaf children is indefensible. Granting this couple's contestable assertion that the deaf ought to be understood as a minority cultural group, allowing individuals to secure the birth of deaf children is supportive of this sociopolitical response to the burdens facing deaf persons. However, the logic underpinning this move also permits individuals to avoid deafness, and in so doing reduces the political power of a deaf culture. Because their action contributes to social injustice, this couple therefore cannot be absolved of responsibility for the harms their children will face on the grounds that these are socially imposed. Thus, it will be argued that those attempting to ensure the birth of deaf children cannot appeal to premise (1) for support.

\section{WHY THIS COUPLE'S DECISION IS INHERENTLY JUST}

Continuing this couple's appeal to the experiences of women is helpful for demonstrating how selection in favour of impairment may be inherently just. A parent's decision to secure either a particular sex or impairment can be respected as a pursuit of a relationship with a child who shares fundamental components of the parent's self identity. In isolation from the social norms, roles, and institutions that lead the sexes to become gendered, Overall points out that a woman's identity is affected by her awareness of certain experiences and capacities that stem from her being biologically female. One example of this is an awareness of the capacity to procreate. $^{3}$ Given the importance of relationships to individual life plans, it therefore does not seem inherently problematic to seek relationships with children who will share "a likeness, an affinity, of experiences and capacities," that give parents "the groundedness of being with [their] own kind". ${ }^{4}$ Indeed, as Overall points out, we routinely prefer a particular sex in terms of personal, or even parent-child relationships without this being deemed sexist."

Similarly, one could argue that excluding the social influences that may lead the impairment of deafness to become disabling, this impairment may itself affect an individual's identity by ensuring distinct experiences and capacities. For example, unlike a hearing child who can sign or lip read, the deaf child's experiences are shaped by an awareness that they are reliant on such techniques to effectively communicate with others. What are alternative modes of communication for one are the main modes of communication for the other. Awareness that one's children share this distinct experience of the world creates an affinity that, as in the case of children's sex, may have a grounding effect for individual parents.

One might agree that such preferences are inherently just, and still contest this argument. Here it could be argued that unlike sex, impairments impose inherent limitations on an individual's ability to access and make use of various opportunities. ${ }^{6}$ Parents ought to be aware of this: thus, in seeking to secure an affinity with their children by ensuring that they are impaired, their preference is inherently unjust in the sense of ensuring avoidable harm.

This argument can be rejected, however, as the limitation of opportunity here is not inherent in the sense of residing solely in the impairment: to be understood as a limitation of opportunity, there must be a social expectation that the activity that is limited ought to be performed. ${ }^{7}$ Further, the failure to meet these expectations is a social matter. For example, if we expect the deaf to be able to use televisions, their lack of hearing is not a loss of opportunity if there is closed captioning for all programmes. Arguing that they lack the opportunity to hear the TV is an empty point without connecting this loss to a disadvantage. When examples of this can be generated, it remains the case that if society were better constructed to accommodate the range of abilities that exist within it, hearing impairments would not be limitations of opportunity. ${ }^{8}$

\section{WHY SELECTION OF DEAF CHILDREN IS INDEFENSIBLE}

Overall argues that inherently just preferences for sex cannot be respected due to their social consequences. ${ }^{9}$ Space limitations prevent discussion of her arguments for this. Instead, whether the selection of impairment should be opposed because of its consequences, will 
be assessed. If this holds, then grounds exist for taking issue with this couple's decision, while granting their premise that it is not wrong to have a child when the harms they will experience are socially imposed. That is, it is possible that allowing for the selection of impairment may create or reinforce the social harms that deaf persons experience. If so, then this couple's argument fails: their contribution to social harms prevents them from appealing to social harm as a justification for absolving them of responsibility for the harms their child will experience if they are deaf.

I will argue that this conclusion follows from this couple's own perspective on the appropriate sociopolitical response to deaf persons. That is, as with women and people of colour, this couple regard the Deaf as both a minority group and a cultural group. ${ }^{10}$ (Author's note: I switch between "deaf" and "Deaf" to acknowledge that when persons with this impairment speak of sharing a community or culture, they describe it as "Deaf culture" or "Deaf community". I feel, however, that we can refer to individuals with the impairment of "deafness" without reference to a deaf community or culture, and so use the term "deaf" where I am not describing this communal or cultural perspective.) Just as impairment may be central to individual identity, and the pursuit of relationships on this basis, the impairment of deafness is understood from a Deaf-culture view as an essential criterion for membership in that culture. ${ }^{11}$ Once situated within a minority group, the Deaf are understood as victims of acts that support the dominance of the majority group. Discriminatory stereotypes of the deaf as unhealthy or less intelligent are one example of this. By identifying individuals with the impairment of deafness as members of a group, they can be protected from discrimination through the extension of legal rights to that group. Further, if the group is understood as a culture, as it is by the parents in this case, then the distinct language, activities, and institutions of that culture may allow for its members to positively value, or revalue, the differences that separate them from the majority.

Identifying people who are deaf as a culture or minority group can, however, have adverse consequences. For example, by demanding a static identification of members of the minority deaf community, and members of the majority community, it obscures the fact that later in life, individuals in the latter group may share similar needs with the former. For example, one may experience deafness or hearing impairment in old age. Political recognition of this results in a larger cohort whose needs will more likely be attended to. ${ }^{12}$

\section{THE CONSEQUENCES OF ALLOWING FOR THE SELECTION OF DEAFNESS}

Granting minority status to the Deaf community can have still worse consequences.

As noted above, the recognition of a Deaf culture is felt to be necessary to protect deaf individuals from burdens imposed by the majority culture. Further, the existence of such a culture is dependent on the ability to distinguish its members from other members of society. Here physical impairment, and positive revaluation of this impairment, are widely accepted criteria for membership in Deaf culture. " By securing the birth of a child with the impairment of deafness, one has therefore ensured the existence of a child with an essential criterion for membership in the Deaf culture. Securing more potential members of the Deaf community will likely lead to a larger Deaf community. Further, as members of the Deaf community have argued, a larger Deaf community may have more political power and secure more protection and services for itself. ${ }^{13}$ Thus, the couple in this case can appeal to a fairly straightforward argument to show that their action promotes social justice for existing persons who are deaf.

The problem with this argument is that it can be run in the reverse direction to allow for avoidance of disability, thus preventing the existence of a child with an essential criterion for membership in the Deaf culture.

Permitting selection in favour of deafness grants that the categories of "impaired individuals" and "non-impaired individuals" have a place in reproductive decision making. This is by no means a necessary move, as distinctively reproductive choices can be defended as those involving the physical ability of an individual to control whether or not they reproduce, and if so, how many children they reproduce. ${ }^{14}$ Stated differently, a reproductive choice is one concerning whether or not a child should exist, not whether a particular child should exist. ${ }^{15}$ By allowing the guarantee of a particular outcome a legitimate place in reproductive decision making, scope exists for the avoidance of the particular outcome of a deaf child.

It is now clear that the same logic underpinning support for the assurance of a deaf child can be employed by arguments supporting the avoidance of children with this impairment. This in itself does not, however, establish that allowing individuals to secure the birth of deaf children will result in a reduction of the power of the deaf as a minority group. For this to occur, selection against deafness will have to outweigh selection in favour of it. Nevertheless, two considerations suggest that this will occur.
First, preferences for avoiding deafness will likely outweigh preferences for ensuring its existence. Second, assistive technologies, such as artificial insemination, which permit attempts to ensure impairment are only utilised in a small percentage of pregnancies, whereas the potential avoidance of deafness through prenatal diagnostic technologies could be utilised in the case of any pregnancy. Indeed, the experience of the American couple in this case speaks to both of these points: in the US, deafness is felt to be sufficiently negative to bar congenitally deaf individuals from donating sperm, a move that led this couple to seek a private donor to provide sperm for artificial insemination. ${ }^{10}$ While they were able to resist this judgment about deafness and use artificial insemination to secure the birth of a deaf child, the attitudes and conditions that prevented their access to resources remain. Potentially, combined with more frequently used reproductive technologies such as prenatal diagnosis, these attitudes will serve to deny potential deaf persons membership in the moral community. This prevents the existence of a child with an essential criterion for membership in the Deaf culture. As a result, these actions will likely lead to a smaller deaf community, which in turn may have less political power and secure less protection and services for itself.

Thus, despite being inherently just, this couple's attempt to ensure the birth of a deaf child should be opposed on consequential grounds. Even granting their contestable understanding of the deaf as a minority culture, allowance for this couple's selective reproductive decision undermines this perspective's attempt to ensure social justice for Deaf persons. Consequently, the social imposition of harm on children cannot be used as a justification for absolving these parents of responsibility for the consequences of their actions: in undermining a minority culture, they contribute to these social harms.

In sum, couples should be allowed to select neither for nor against deafness.

J Med Ethics 2002;28:286-288

................

Author's affiliations

K W Anstey, Centre for Applied Philosophy and Public Ethics, Department of Philosophy, The University of Melbourne, Parkville, Victoria, Australia 3010;

k.anstey@pgrad.unimelb.edu.au

\section{REFERENCES AND NOTES}

1 Spriggs $M$. Lesbian couple create a child who is deaf like them. Journal of Medical Ethics Online eCurrent Controversies, 2002 May 2: Mundy L. A world of their own. The Washington Post 2002 Mar 31: W22. 2 See reference 1: Spriggs $M$.

3 Overall C. Ethics and human reproduction: a feminist analysis. Boston: Allen \& Unwin,

1987: 25-27. Although some women lack 
this capacity, their identity will nevertheless be shaped by their awareness of this.

4 See reference 3: 26

5 See reference 3: 24

6 This argument is often articulated as the assurance of a "right to an open future," the selection of the "best potential child," or the obligation to "reduce suffering and limitations of opportunity in the world". See

Davis DN. Genetic dilemmas and the child's right to an open future. Hastings Centre Report 1997;27:7-15; Savulescu J. Procreative beneficence: why we should select the best children Bioethics 2001;15:413-26; Harris J. Wonderwoman and Superman: the ethics of human biotechnology. Oxford: Oxford University Press, 1992.

7 See Bickenbach JE, Chatterii S, Badley EM, et al. Models of disablement, universalism, and the international classification of impairments, disabilities, and handicaps. Social Science and Medicine 1999;48: 1173-87

8 Some will resist this conclusion, and point out that some experiences remain closed off to the deaf regardless of changes in social support to those with this impairment. Indeed, the account of identity argued for above presupposes an inherent prevention of certain experiences. The prevention of experience is not, however, synonymous with the prevention of opportunity. Indeed, as I have argued elsewhere, surely it is not the availability of particular opportunities, or the mere number of available opportunities, that is ethically significant, but instead the individual's ability to pursue opportunities associated with the projects and relationships that serve their life plans. Anstey KW. Sex selection and disability avoidance: is their opposed treatment

conceptually consistent? Monash Bioethics Review 2002;21:10-28. Where certain life plans appear to be closed off by impairment, it is important to bear in mind the possibility of the individual participating in "alternative modes of those same activities". See Asch A. Prenatal diagnosis and selective abortion: a challenge to practice and policy. American Journal of Public Health 1999;89: 1649-57. For example, while the deaf may not be able to appreciate musical pleasures, they may experience the artistic enjoyment in the visual arts. Further, hearing impairments may open particular opportunities to those possessing them. For example, there is conflicting research on the issue of whether the deaf have enhanced visual perception skills. See Rettenbach R, Diller G, Sireteanu R. Do deaf people see better? Texture segmentation and visual search compensate in adult but not in juvenile subjects. Journal of Cognitive Neuroscience 1999;11:560-83.

9 Overall C. Ethics and human reproduction: a feminist analysis. Boston: Allen \& Unwin 1987: 25-27.

10 Mundy L. A world of their own. The Washington Post 2002 Mar 31 : W22.

11 In addition to being born or becoming deaf, identifying as Deaf, and participation in the activities of Deaf culture are widely viewed as necessary to gain and continue membership in Deaf culture. See Newell C.
Access to opportunity or oppression? An Australian policy analysis of the ethics of the cochlear implant. Interaction 2000;13:16-23; Padden C, Humphries T. Deaf in America: voices from a culture. Cambridge, MA: Harvard University Press, 1988; Tucker BP. Deaf culture, cochlear implants, and elective disability. Hastings Center Report 1998;28:6-14

12 For a good critique of minority group approaches to impairment and disabilities, see reference 7 .

13 To be sure, the linkage between group size and political power is contestable. A study of political activism in an American deaf community found, however, that its small size was viewed as a major barrier to political recognition and access to sufficient services. See Bateman GC. Community issues and political activism. In: Garretson M, ed. Viewpoints on deafness [Deaf American monograph No 2]. Silver Spring, MD: National Association of the Deaf, 1992: 19-23.

14 Coleman notes that this is the extent to which the US Supreme Court has recognised a principle of procreative liberty. See Coleman C. Is there a constitutional right to preconception sex selection? American Journal of Bioethics 2001;1:27-8.

15 For a discussion of this "any/particular" distinction, see Parens E, Asch A. The disability rights critique of prenatal genetic testing: reflections and recommendations. Hastings Center Report 1999;29(supp):122S. 